University of Nebraska - Lincoln

DigitalCommons@University of Nebraska - Lincoln

Biological Systems Engineering--Dissertations,

Theses, and Student Research

Biological Systems Engineering

March 2008

\title{
An Adaptive Neuro-Fuzzy Inference System for Modeling Mechanical Properties of Tapioca Starch-Poly(Lactic Acid) Nanocomposite Foams
}

\author{
Siew-Yoong Lee \\ University of Nebraska at Lincoln, siew18@gmail.com \\ Milford Hanna \\ University of Nebraska-Lincoln, mhanna1@unl.edu \\ David D. Jones \\ University of Nebraska - Lincoln, david.jones@unl.edu
}

Follow this and additional works at: https://digitalcommons.unl.edu/biosysengdiss

Part of the Biological Engineering Commons

Lee, Siew-Yoong; Hanna, Milford; and Jones, David D., "An Adaptive Neuro-Fuzzy Inference System for Modeling Mechanical Properties of Tapioca Starch-Poly(Lactic Acid) Nanocomposite Foams" (2008). Biological Systems Engineering--Dissertations, Theses, and Student Research. 2.

https://digitalcommons.unl.edu/biosysengdiss/2

This Article is brought to you for free and open access by the Biological Systems Engineering at DigitalCommons@University of Nebraska - Lincoln. It has been accepted for inclusion in Biological Systems Engineering--Dissertations, Theses, and Student Research by an authorized administrator of DigitalCommons@University of Nebraska - Lincoln. 
Published in Starch/Stärke 60 (2008), pp. 159-164; doi 10.1002/star.200700687. Copyright @ 2008 WILEY-VCH Verlag GmbH \& Co. KGaA, Weinheim. Used by permission. http://www3.interscience.wiley.com/journal/5007532/home

\title{
An Adaptive Neuro-Fuzzy Inference System for Modeling Mechanical Properties of Tapioca Starch-Poly(Lactic Acid) Nanocomposite Foams
}

\author{
Siew Yoong Lee, ' Milford A. Hanna,' and David D. Jones ${ }^{2}$ \\ I University of Nebraska-Lincoln, Industrial Agricultural Products Center and Biological Systems Engineering Department, Nebraska, USA \\ 2 University of Nebraska-Lincoln, Biological Systems Engineering Department, Nebraska, USA \\ Corresponding author: M.A. Hanna, tel 402 472-I634, fax 402 472-6338, email mhannal@unl.edu
}

\begin{abstract}
Tapioca starch, poly(lactic acid) and Cloisite 30B nanocomposites foams, with clay contents of I, 3, 5 and 7\% (w/w), were prepared by a meltintercalation method. Multiple inputs single output models were developed to predict radial expansion ratio, unit density, bulk compressibility and spring index of the nanocomposite foams. An individual ANFIS model was developed for each mechanical property using clay content, temperature, pressure and torque as input parameters. All models preformed well with $R^{2}$ values $>0.7 \mathrm{l}$. All models had very low root mean squared error values.
\end{abstract}

Keywords: modeling, clay, temperature, pressure, torque

\section{Introduction}

Poly(lactic acid) (polylactate or polylactide) (PLA) is a polyester, and is synthesized from L- and D-lactic acids, which are produced from the fermentation of sugar and (poly)saccharides such as sugar feedstocks and corn, wheat and other starches. The lactic acid is converted to PLA either by ring-opening polymerization of lactide (formed by condensation of two lactic acid entities) or by condensation polymerization. PLA is insoluble in water and has good moisture and grease resistance. PLA is used widely as a biodegradable and renewable plastic for uses in service ware, grocery, waste-composting bags, mulch films, controlled release matrices for fertilizers, pesticides and herbicides [I].

Starch is an inexpensive and readily available resource, and is often used as a filler for the replacement of petroleum-derived synthetic polymers to decrease environmental pollution. However, starch has severe limitations because of its water solubility and poor water-resistance, making starch products very sensitive to the relative humidity at which they are stored and used [2]. Starch-polyester blends are being produced with the objective of maintaining the excellent physical properties of the polyesters while reducing cost. A process was developed at the University of Nebraska-Lincoln to produce starchbased plastic foam with $70 \%$ starch combined with a variety of ingredients and plastics [3]. Fang and Hanna [4] found that addition of PLA to regular and waxy corn starches improved the physical and mechanical properties of the foams. More recently, formation of nanocomposites with the aim of improving functional properties has become popular.

Polymer nanocomposites are a class of reinforced polymers containing small quantities ( $1-5 \%, \mathrm{w} / \mathrm{w})$ of nanometricsized clay particles. The functional properties of the nanocomposites are improved markedly compared to those of the unfilled polymer or conventional composites. These improvements include high moduli $[5,6]$; increased tensile strength [7] and thermal stability [8]; decreased gas permeability [9] and flammability [10]; and increased biodegradability of biodegradable polymers [II].

Melt intercalation by extrusion is the most common approach to synthesize nanocomposites because it is an environmentally-friendly process that requires no solvent and is suitable for industrial uses [12, 13]. Extrusion processing is considered to be more of an art than science.

Numerous studies have reported on the complexities of the extrusion process and modeling of the process. Extrusion cooking can be described as a process whereby moistened materials are cooked and worked into viscous, plastic-like dough. Cooking is accomplished through the application of heat, either directly by steam injection or indirectly through jacketed barrels and by dissipation of mechanical energy through shearing of the dough [14].

Mathematical modeling of the extrusion process began in the fields of plastic and polymer engineering. Because of the 
complexity of the extrusion process, complex mathematical models have been proposed to describe the process. In recent years, new modeling tools like fuzzy modeling have been developed. Fuzzy modeling in extrusion is challenging due to the complexity of the process which consists of multiple inputs and multiple outputs which are highly non-linear. Fuzzy modeling makes it possible to utilize experience, knowledge and large amounts of process data. Artificial neural networks have been used to model and identify predictive models for a food extrusion process [15], control a food extrusion process [16] and for polymer extrusion [17].

In this study, we present a novel neuro-fuzzy approach, i.e. adaptive network-based fuzzy inference system (ANFIS), to model extrusion of nanocomposite foams. ANFIS is a fuzzy inference system implemented in the framework of an adaptive neural network. By using a hybrid learning procedure, ANFIS can construct input-output mapping based on both human-knowledge as fuzzy If-Then rules and given input-output data pairs for neural networks training [18]. ANFIS is a powerful tool in fuzzy modeling to learn information about the given input and output data sets in order to compute the membership functions that describe the associated fuzzy inference system.

The objectives of this study were to prepare tapioca starch/PLA/Cloisite 30B nanocomposite foams of different clay contents via extrusion, to investigate the influence of clay content on the mechanical properties of the foams and to use ANFIS to model the clay content, temperature, pressure and torque on the mechanical properties of the foams.

\section{Materials and Methods}

\section{I Materials}

Semicrystalline poly(lactic) acid (PLA) resin of $\mathrm{MW}_{n} 85,000$ was produced by Cargill, Inc. (Minneapolis, MN, USA). It contained $\sim 93 \%$ L-lactide, $2 \%$ D-lactide and $5 \%$ meso-lactide. Commercially available tapioca starch (17\% amylose and $83 \%$ amylopectin) was purchased from Starch Tech, Inc. (Golden Valley, MN, USA). Tapioca starch was agglomerated into spherical granules of 2-4 mm diameter to facilitate feeding into the extruder. The moisture content of the tapioca starch was adjusted to $18 \%$, dry basis, with distilled water prior to extrusion. Tapioca starch, PLA, sodium bicarbonate, citric acid and clay were blended in a Hobart mixer (Model C-100, Horbart Corp., Troy, OH, USA) and stored in plastic jars prior to extrusion. A PLA content of $10 \%$ was selected based on preliminary experiments. Fang and Hanna [19] used three levels of polymer content (10,25 and 40\%) in their study of mechanical properties of starch-based foams. They found that, at 10\% PLA content, the foams possessed the highest spring index and intermediate compressibility and Young's modulus. Sodium bicarbonate $(0.5 \%)$ and citric acid $(0.5 \%)$ were added to degrade the biodegradable polymer into chains of between 1,000 and 100,000 Da or approximately 500 to 50,000 monosaccharide groups to promote expansion [3]. Organically modified montmorillonite under the trade name of Cloisite 30B (methyl-tallow-bis-2hydroxyethyl ammonium) (MT2EtOH) was purchased from Southern Clay Products Inc. (Gonzalez, TX, USA). The particle size range of the nanoclay was $2-13 \mu \mathrm{m}$. Four different relative contents of Cloisite $30 \mathrm{~B}$ (I, 3, 5 and 7\%, w/w) were added to the formulation. The PLA and the nanoclay were dried at $70^{\circ} \mathrm{C}$ for at least $24 \mathrm{~h}$ before preparing the formulations.

\subsection{Extrusion}

A twin-screw extruder (Model DR-2027-KI3, C. W. Brabender, Inc., S. Hackensack, NJ, USA) with corotating mixing screws (Model CTSE-V, C.W. Brabender, Inc., S. Hackensack, NJ, USA) was used to conduct extrusions. The conical screws had diameters decreasing from $43 \mathrm{~mm}$ to $28 \mathrm{~mm}$ along their length of $365 \mathrm{~mm}$ from the feed end to the exit end. On each screw, there was a mixing section, in which small portions of the screw flights were cut away. The mixing section enhanced mixing and also increased the residence time of the sample in the barrel. A 150-rpm screw speed was used for all extrusions. The temperature at the feeding section was maintained at $50^{\circ} \mathrm{C}$, the second barrel section at $120^{\circ} \mathrm{C}$, the third barrel section at $150^{\circ} \mathrm{C}$ and the die section at $170^{\circ} \mathrm{C}$. A $3 \mathrm{~mm}$ diameter die nozzle was used to produce continuous cylindrical rope-like extrudates, which were cut by a rotary cutter. The extruder was controlled by a Plasti-Corder (Type FE 2000, C.W. Brabender, Inc. S. Hackensack, NJ, USA).

Temperature profiles, pressure profiles and torque readings were recorded for fuzzy modeling. Extrusion conditions selected were based on preliminary studies and previous experiments.

\subsection{Radial expansion ratio (RER)}

RERs of the extruded foams were calculated by dividing the mean cross-sectional areas of the extrudates by the crosssectional area of the die nozzle. Each calculated value was a mean of 20 observations.

\subsection{Unit density (UD)}

Unit density of the extrudates were determined using a glass bead displacement method [20]. The glass beads had $0.1 \mathrm{~mm}$ diameter. Mean values of UD were obtained by averaging five replicates. 


\subsection{Bulk spring index (SI)}

BSI measurements were made using an Instron universal testing machine (Model 5566, Instron Engineering Corp., Canton, MA, USA). A cylindrical aluminum container with a volume of $365 \mathrm{~cm}^{3}$ (6.93 cm in diameter and $9.68 \mathrm{~cm}$ in depth) was used to confine the bulk samples. The forces required to initially compress the samples to $80 \%$ of their original volumes and the forces required to recompress the same samples I min after releasing the initial load were recorded. BSI was calculated by dividing the recompression force by the initial compression force and has an ideal value of I. A mean value was obtained by averaging five replicates.

\subsection{Bulk compressibility (BC)}

Bulk compressibility was calculated using the same data collected in the BSI test. It was calculated by dividing the peak force required to compress (deform) the sample by $80 \%$ [to $20 \%$ of their original dimension (diameter)] by the initial axial cross-sectional area of the foams [19]. A mean value was obtained by averaging five replicates.

\subsection{ANFIS modeling}

Modeling was performed using Matlab 7.2. ANFIS and Sugeno-type fuzzy inference systems were used in the modeling of properties of the nanocomposite foams. Multiple Input Single Output (MISO) models consisting of four inputs including clay content, temperature, pressure and torque were developed to predict outputs. Figure I shows the ANFIS structure of clay content and process parameters as four input parameters and four mechanical properties as output parameters. The outputs were RER, UD, SI and BC. Sugeno-type fuzzy inference systems were generated by using Genfis2 (Matlab fuzzy logic toolbox) which utilized subtractive clustering to compute the models for the product properties. The purpose of clustering was to identify natural groupings of data to produce a concise representation of the behavior of the system [2I].

The fuzzy models generated from the membership functions and rules were data-driven by the process data for each mechanical property. Each set of process data collected from the extrusions consisted of 80 data points from which $70 \%$ and $30 \%$ were selected randomly for training and testing, respectively. The models were developed and implemented using 300 epochs and a radius of 0.5 . The input data were the process data acquired by the computer consisting of temperature, pressure and torque readings from extrusion. The input data also consisted of the clay contents. The output data were the properties consisting of RER, UD, $\mathrm{SI}$ and $\mathrm{BC}$.

The input and output data sets contained four inputs [clay content $(\%)$, melt temperature $\left({ }^{\circ} \mathrm{C}\right)$, pressure $(\mathrm{kPa})$, torque $(\mathrm{Nm})]$ and one output (RER). The same data sets were used for each mechanical property, namely UD, SI and BC. Tab. I gives the experiment results of clay content and process parameters as four input parameters and four properties as output parameters. Predicted values for each model were produced using the 'evalfis' function of Matlab software. Models developed were evaluated by the $R^{2}$ of prediction and root mean squared error (RMSE).

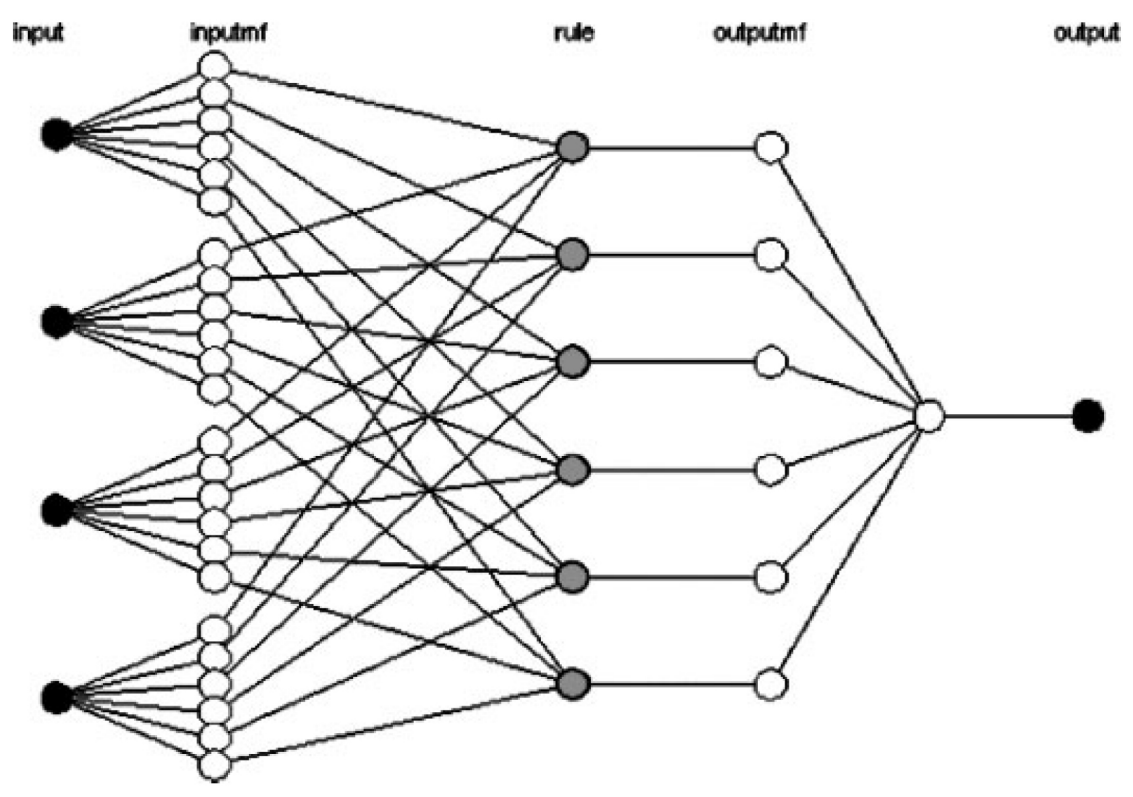

Figure I. ANFIS model structure for radial expansion ratio. 
Table I. $R^{2}$ and RMSE values for training and testing of ANFIS models for product properties.

\begin{tabular}{lcccc}
\hline Product property & $\begin{array}{c}R^{2} \\
\text { (Training) }\end{array}$ & $\begin{array}{c}\text { RMSE } \\
\text { (Training) }\end{array}$ & $\begin{array}{c}R^{2} \\
\text { (Testing) }\end{array}$ & $\begin{array}{c}\text { RMSE } \\
\text { (Testing) }\end{array}$ \\
\hline Radial expansion ratio & 0.9857 & 0.0641 & 0.7682 & 0.8590 \\
Unit density & 0.9431 & 1.1206 & 0.7128 & 0.4260 \\
Spring index & 0.9953 & 0.0286 & 0.9926 & 0.0317 \\
Bulk compressibility & 0.9998 & 0.0185 & 0.8821 & 0.5539 \\
\hline
\end{tabular}
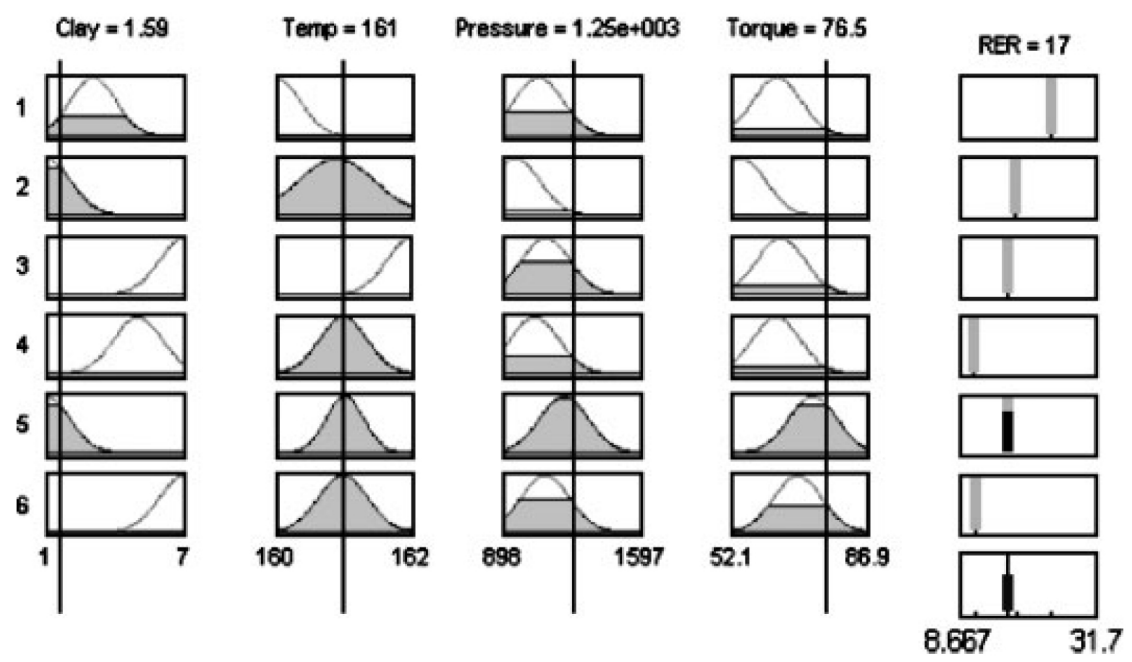

Figure 2. Rule viewer for radial expansion ratio.

\section{Results and Discussion}

Multiple Input Single Output (MISO) models were developed to predict each property separately from the input parameters (clay content, temperature, pressure and torque). These models were computed based on the input and output data that were used to train the model. The patterns were tuned using a hybrid system that contained a combination of the back propagation and least-squares-type methods. An error tolerance of 0 was used and the number of epochs was 300. After training and testing, the RMSE became steady, the training and testing were regarded as converged [22]. The predicted output values from the models were obtained for training and testing using the 'evalfis' function of Matlab software. Models developed were evaluated by the $R^{2}$ of prediction and RMSE values. Figure I shows the ANFIS model structure of RER which had four inputs and one output. Each input was connected to six membership functions, and further networked with six rules. Each rule was connected with one membership function and these membership functions generated the output. Figure 2 shows the rule viewer of RER which is a mapping of inputs and output that describes the fuzzy inference system. Each row in the figure represents one rule and consists of four membership functions correspond- ing to each of the four inputs (clay, temperature, pressure and torque). The membership functions are shown in the first four columns which also are known as antecent memberships. The last column is the output (RER) also known as consequent membership, which represents inputs of each of the six rules. The rule viewer shows only one calculation at a time in detail. In this example, the input values for the rule viewer were data driven values of 1.59 for clay, $161^{\circ} \mathrm{C}$ for temperature, $8618 \mathrm{kPa}$ for pressure and $76.5 \mathrm{Nm}$ for torque. The calculated value for the model RER was 17.

For each individual membership function, the range of input values was represented by values on the $x$-axis and membership value represented on the $y$-axis. The shaded region depicted the visual representation of the resulting membership of input values. In fuzzy modeling, input membership functions can be described by different shapes including triangular, sigmoidal, bell-shaped or irregular [23]. In this work, the input membership functions were described with Gaussian membership functions. The model used a logical 'AND' relationship to combine the data space into fuzzy clusters. The portion of the bar of the last column represents the weighting factor for that rule, and is determined by the minimum membership value in each rule. For example, in Rule I, the shaded region of the clay membership function was zero. 
Therefore, this rule did not contribute to the firing strength. Similarly, Rule 2 did not contribute to the firing strength. Rule 3 and 4 contributed to about 15 and $10 \%$ of the contribution, respectively. In Rule 5 , the shaded regions of the clay and torque membership functions were about $90 \%$, showing this rule had a strong firing strength. In the Sugeno fuzzy inference system, every rule contributes to predicting the output to a certain degree based on the degree of membership of the input values to the input fuzzy sets. A single output was defuzzified using the center of gravity or a weighted average of output from each of the six rules, and is shown in the lower right hand corner. Therefore, for the RER model, clay content and torque had the greatest impacts on RER. Figure 3 shows the surface plot of RER as a function of clay content and torque. This surface plot shows that RER had a complex and nonlinear nature based on the relationships between the inputs [24].

Figs. 4 through 7 show the plots of predicted versus actual values for all properties for testing data using the MIMO models. All the plots show relatively good accuracy. Tab. I shows the $R^{2}$ and RMSE values for testing and training of ANFIS for all product property models. For RER, comparison of predicted values with the actual values produced $R^{2}$ values of 0.9857 and 0.7682 for training and testing data, respectively. As can be observed, the $R^{2}$ values for training for all the properties were higher than the $R^{2}$ values of testing suggesting that a bigger set of data produced better models.

RMSE values of $0.064 \mathrm{I}$ and 0.8590 were achieved for training and testing, respectively, for RER. All models had very low RMSE values for both training and testing. Models with the highest $R^{2}$ and minimum RMSE values were considered the best models. Once trained and tested, the ANFIS models can be used to predict the outputs expected for new levels of input parameters

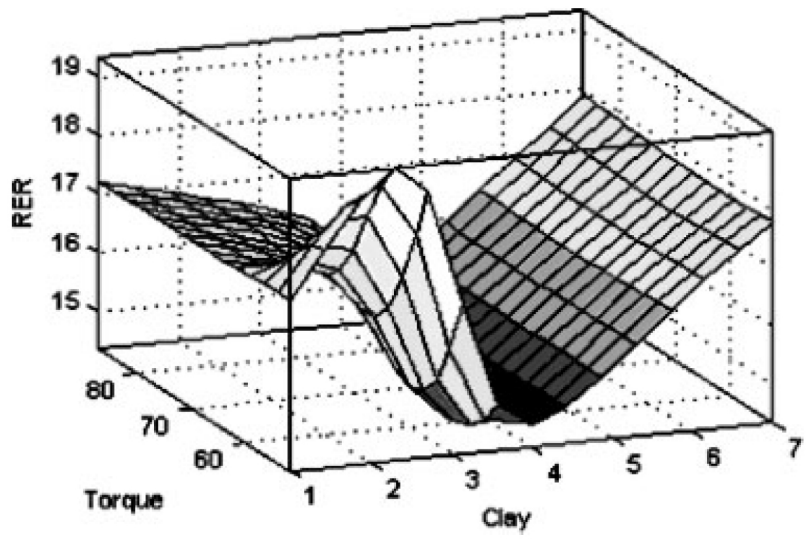

Figure 3. Surface plot of radial expansion ratio mapping the relationship between clay content and torque.

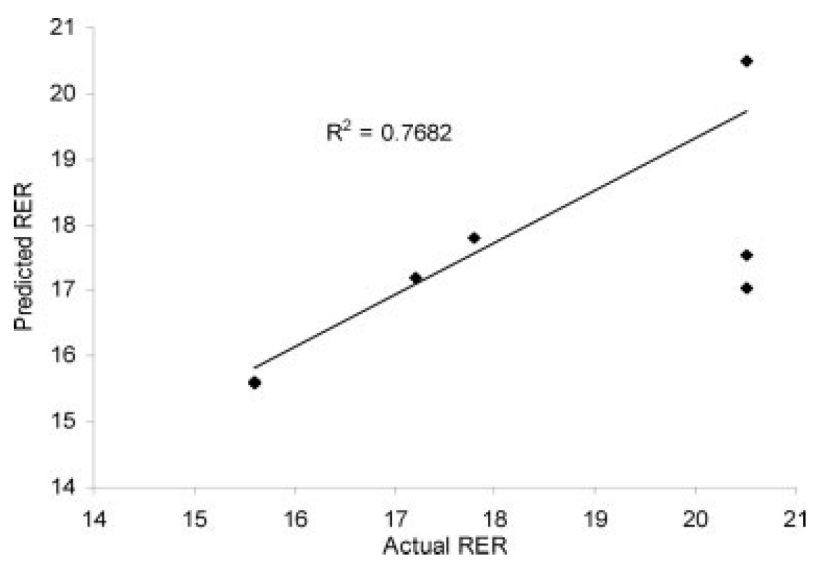

Figure 4. Relationship between predicted values of radial expansion ratio and actual values.

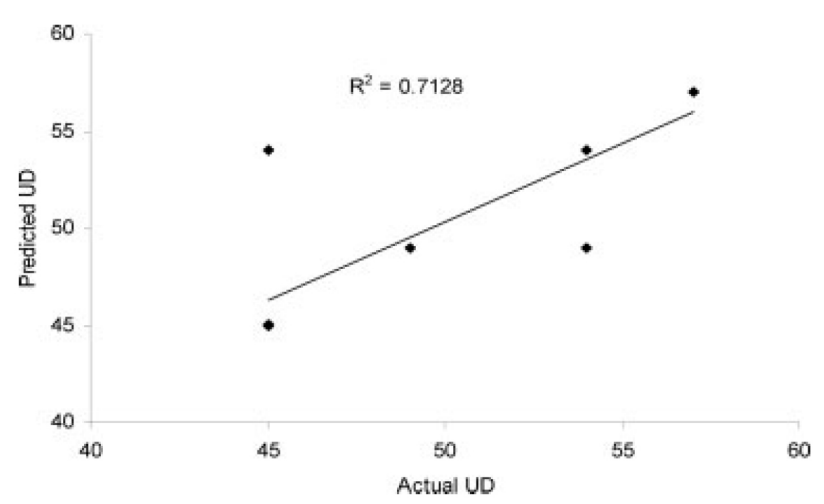

Figure 5. Relationship between predicted values of unit density and actual values.

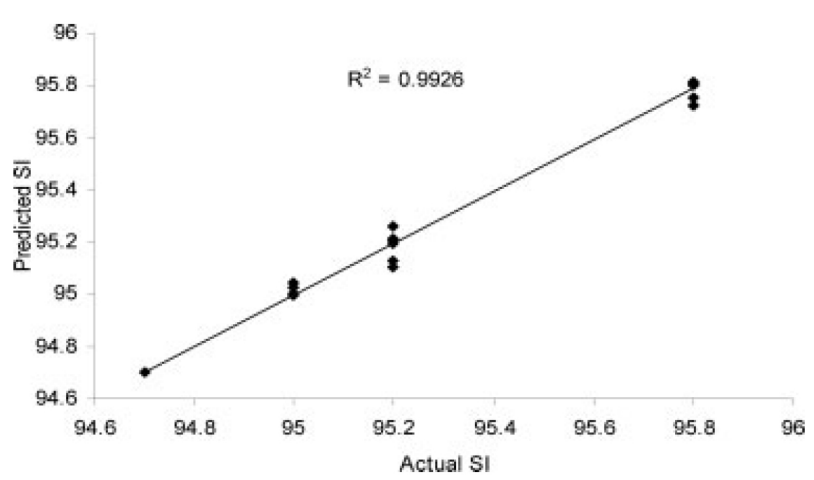

Figure 6. Relationship between predicted values of spring index and actual values.

\section{Conclusions}

The results obtained indicate that ANFIS is a promising tool for modeling extrusion of biodegradable nanocomposite foams. ANFIS models were developed for selected mechanical properties of tapioca starch-PLA nanocomposite foams using different clay contents and process parameters. Individual models were developed predicting radial expansion ratio, 


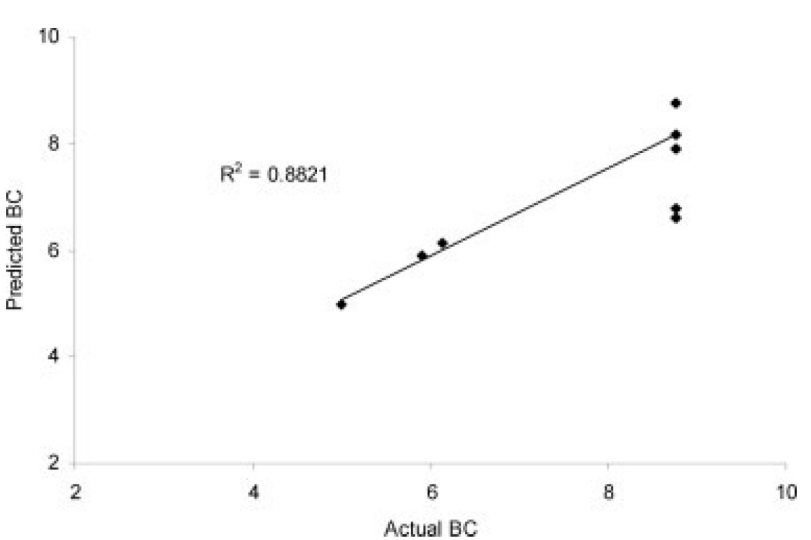

Figure 7. Relationship between predicted values of bulk compressibility and actual values.

unit density, spring index and bulk compressibility. The $R^{2}$ values for training for all the mechanical properties were higher than the $R^{2}$ values of testing suggesting that a bigger set of data produced better prediction of the models. All models preformed well with $R^{2}$ values $>0.7 \mathrm{I}$ for testing. All models had very low RMSE values for both training and testing. Models with the highest $R^{2}$ and minimum RMSE values were considered the best models. These models serve as tools for predicting the input levels needed to generate a desired property.

\section{Acknowledgments}

This manuscript is a contribution of the University of Nebraska Agricultural Research Division, supported in part by funds provided through the Hatch Act, USDA. Mention of trade names, propriety products, or company name is for presentation clarity only and does not imply endorsement by the authors or the University of Nebraska.

\section{References}

[I] Q. Fang, M.A. Hanna: Rheological properties of amorphous and semicrystalline poly(lactic acid) polymers. Ind. Crops Prod. I 999, 10,47-53.

[2] S. Simmons, E. L. Thomas: Structural characteristics of biodegradable thermoplastic starch/poly(ethylene-vinyl alcohol) blends.J. Appl. Polym. Sci. 1 995, 58, 2259-2285.

[3] R. Chinnaswamy, M.A. Hanna: U.S. Pat. 496,895 (1993).

[4] Q. Fang, M.A. Hanna: Mechanical properties of starch-based foams as affected by ingredient formulations and foam physical characteristics. Trans. ASAE 2000, 43, 1715-1723.

[5] Y.T. Lim, O. O. Park: Rheological evidence for the microstructure of intercalated polymer/layered silicate nanocomposites. Macromol. Rapid Commun. 2000, 2I, 23 I-235.

[6] P. H. Nam, P. Maiti, M. Okamoto, T. Kotaka, N. Hasegawa, A. Usuki: A hierarchical structure and properties of intercalated polypropylene/clay nanocomposites. Polymer 200 I, 42, 9633-9640.
[7] H. R. Dennis, D. L. Hunter, D. Chang, S. Kim, J. L.White, J.W. Cho, D. R. Paul: Effect of melt processing conditions on the extent of exfoliation in clay-based nanocomposites. Polymer 200 I, 42, 9513-9522.

[8] J- H. Chang, T- G. Jang, K. J. Ihn, W- K. Lee, G. S. Sur: Poly(vinyl alcohol) nanocomposites with different clays: Pristine clays and clays.J.Appl. Polym. Sci., 2003, 90, 3208-32I4.

[9] J- H.Yuen, G- S. Bang, B. J. Park, S. K. Ham, J- H. Chang: Poly(vinyl alcohol) nanocomposite films:Thermo optical properties, morphology, and gas permeability. J.Appl. Polym. Sci. 2006, I0I, 59I-596.

[10] A. B. Morgan: Flame retarded polymer layered silicate nanocomposites: A review of commercial and open literature systems. Polym.Adv.Technol. 2006, 17, 206-217.

[I I] S. S. Ray, K. Yamada, M. Okamoto, K. Ueda: Control of biodegradability of polylactide via nanocomposite technology. Macromol. Mater. Eng. 2003, 288, 203-208.

[12] W. M. Choi, T.W. Kim, O. O. Park, Y. K. Chang, J.W. Lee: Preparation and Characterization of poly(hydroxybutyrateco- hydroxyvalerate)-clay nanocomposite. J. Appl. Polym. Sci. 2003, 90 , 525-529.

[13] X. C. Li, C- S. Ha: Nanostructure of EVA/clay nanocomposites: Effects of kinds of clay and grafting of maleic anhydride onto EVA.J.Appl. Polym. Sci. 2003, 87, 1901-1909.

[14] J. M. Harper: Food Extrusion, in Extrusion of Foods, Vol. I, CRC Press, Inc. Boca Raton, FI. I98I.

[15] G. M. Ganjyal, M.A. Hanna, D. D. Jones: Modeling selected properties of extruded waxy maize cross-linked starches with neural networks.J. Food Sci. 2005, 68, I 384-1388.

[16] O. Popescu, D. C. Popescu, J.Wilder:A new approach to modeling and control of a food extrusion process using artificial neural network and an expert system.J. Food Process Eng. 200 I, 24, 17-36.

[17] H.-X. Huang, S. Lu: Modeling parison formation in extrusion blow molding by neural networks. J. Appl. Polym. Sci. 2005, 96 , 2230-2239.

[18] J- S. R. Jang:ANFIS:Adaptive-network-based fuzzy inference system. IEEE Transactions on Systems, Man and Cybernetics I993, 23, 665-685.

[19] Q. Fang, M.A. Hanna: Functional properties of poly(lactic acid) starch-based loose-fill packaging foams. Cereal Chem. 2000, 77, 779-783.

[20] S. Bhatnagar, M.A. Hanna: Effect of lipids on physicochemical properties of extruded corn starch. ASAE Paper No., 91654I, ASAE, St. Joseph, Mich., 1991.

[2I] V. S. Sharma, S. K. Sharma, A. K. Sharma:An approach for condition monitoring of a turning tool. Proc. IMechE Vol. 22I Part B: J. Eng. Manufacture 2007, 636-646.

[22] G. Daoming, J. Chen:ANFIS for high-pressure waterjet cleaning prediction. Surf. Coat. Technol. 2006, 20I, 1629- 1634.

[23] E. Cox: The Fuzzy Sytems Handbook:A Practitioner's Guide to Building, Using and Maintaining Fuzzy Systems, Academic Press, San Diego, CA, 1994.

[24] M.A. Ghoush, M. Samhouri, M.Al-Holy, T. Herald: Formulation and fuzzy modeling of emulsion stability and viscosity of a gumprotein emulsifier in a model mayonnaise system.J. Food Sci. 2008, 84, 348-357. 